\title{
Globe
}

Revue internationale d'études québécoises

\section{Femmes et féminisme}

\section{Daniel Chartier}

Volume 3, numéro 2, 2000

Le vingtième siècle québécois des femmes

URI : https://id.erudit.org/iderudit/1000577ar

DOI : https://doi.org/10.7202/1000577ar

Aller au sommaire du numéro

Éditeur(s)

Globe, Revue internationale d'études québécoises

ISSN

1481-5869 (imprimé)

1923-8231 (numérique)

Découvrir la revue

Citer ce document

Chartier, D. (2000). Femmes et féminisme. Globe, 3(2), 9-9.

https://doi.org/10.7202/1000577ar d'utilisation que vous pouvez consulter en ligne.

https://apropos.erudit.org/fr/usagers/politique-dutilisation/ 


\section{Présentation Femmes et féminisme}

"Qu'allons-nous devoir imaginer pour jouir et profiter de notre jeune sujet à l'œuvre?", se demande la poète Nicole Brossard dans son avant-propos à ce numéro sur «Le vingtième siècle québécois des femmes ", que dirigeaient Chantal Maillé de l'Institut Simone de Beauvoir et Chantal Savoie du Centre de recherche en littérature québécoise.

Les textes réunis ici portent sur "le changement et les modulations " et s'offrent comme différentes études sur les actions et les réflexions liées aux femmes au cours du dernier siècle. Qu'il s'agisse de démocratie, de citoyenneté, de féminisme, des mouvements de femmes, de la famille ou encore du statut de l'écrivaine, de la présence du féminisme dans les œuvres destinées à la jeunesse ou d'arts visuels, la réflexion sur les femmes et le féminisme caractérise les avancées et les révolutions qui ont marqué la situation des femmes québécoises.

Après ce dossier, on trouvera quelques recensions sur des ouvrages qui abordent ailleurs la question des femmes, ainsi que sur d'autres sujets liés aux études québécoises.

Daniel CHARTIER directeur

GLOBE, Revue internationale d'études québécoises

Chercheur associé Institut national de la recherche scientifique - Urbanisation, culture et société 